\title{
Genetics of Charcot-Marie-Tooth disease type 4A: mutations, inheritance, phenotypic variability, and founder effect
}

\author{
R Claramunt, L Pedrola, T Sevilla, A López de Munain, J Berciano, A Cuesta, B Sánchez-Navarro, \\ J M Millán, G M Saifi, J R Lupski, J J Vílchez, C Espinós, F Palau
}

s arcot-Marie-Tooth (CMT) disease is a motor and sensory neuropathy with clinical and genetic heterogeneity. Patients usually present in the first or second decade of life with distal muscle atrophy in the legs, areflexia, foot deformity (mainly pes cavus), and steppage gait. In most cases, hands are also involved as the disease progresses. CMT is the most frequent inherited neuropathy, with a prevalence in Spain of 28 in $100000 .{ }^{1}$ Based on electrophysiological studies and histopathologic findings in nerve biopsies, CMT has been subcategorised into two main and distinct neuropathies: (i) demyelinating CMT (CMT1, MIM 118200) associated with reduction in a nerve conduction velocities (NCVs) in all nerves and segmental demyelination and remyelination ("onion bulbs"); and (ii) axonal CMT (CMT2, MIM 118220) associated with normal or almost normal NCVs and loss of myelinated axons. Other phenotypes are associated with motor and sensory nerve involvement: Déjérine-Sottas neuropathy (DSN, MIM 145900) is a severe demyelinating neuropathy with onset in infancy, delayed motor milestones, and NCVs less than $10 \mathrm{~m} / \mathrm{s}$; congenital hypomyelinating neuropathy (CHN, MIM 605253) is a dysmyelinating neuropathy characterised by infantile hypotonia, distal muscle weakness, and marked reduction of NCVs; hereditary neuropathy with liability to pressure palsies (HNPP, MIM 162500) is a milder sensory and motor neuropathy with periodic episodes of numbness, muscular weakness, and atrophy. ${ }^{2}$

Genetic heterogeneity is characteristic of the disease not just because of the large number of genes and loci associated with CMT (currently 21 genes), ${ }^{3-5}$ but also because the disease may segregate with different Mendelian patterns. The most frequent pattern of inheritance is autosomal dominant, but autosomal recessive and $\mathrm{X}$ linked segregation are also observed.

The relationship of the type of CMT, demyelinating or axonal, with specific genes is not perfect. For instance, $M P Z$ mutations are usually manifested clinically as an autosomal dominant demyelinating neuropathy, CMT1B. ${ }^{67}$ However, some mutations in MPZ have also been found in patients with axonal neuropathy $\left(\mathrm{CMT} 2-\mathrm{P}_{0}\right){ }^{8}{ }^{8}$ Moreover, some patients with mutation in MPZ expressed the disease as either DSN or CHN. ${ }^{10}{ }^{11}$ On the other hand, mutations in the same gene may be expressed with a different Mendelian pattern. Mutations in the PMP22 gene are expressed as dominant mutations, but there are some mutations in PMP22 that convey an autosomal recessive trait. ${ }^{12}{ }^{13}$

CMT disease caused by mutations in the gangliosideinduced differentiation-associated protein 1 (GDAPl) gene is a severe autosomal recessive neuropathy originally reported in families with either demyelinating CMT4A neuropathy (MIM 214400) ${ }^{14}{ }^{15}$ or axonal neuropathy with vocal cord paresis (MIM 607706), ${ }^{16}$ which maps to the CMT4A locus on

\section{Key points}

- We investigated the genetics and inheritance of the GDAPl gene and phenotype expression in a series of 106 isolated and 19 familial cases with CharcotMarie-Tooth disease and Spanish ancestry, for whom mutations in the PMP22, MPZ, and GJB1 genes had previously been excluded.

- We also investigated the existence of founder effects for some recurrent mutations and the origin of these mutations in patients from different countries.

- We found mutations in seven isolated patients, three autosomal recessive families, and two autosomal dominant families. Six out of seven isolated patients were homozygotes or compound heterozygotes with autosomal recessive inheritance and one patient carried a de novo dominant mutation. The mutation detection rate in the sporadic patients was $5.6 \%$. Patients with homozygous or compound heterozygous genotypes showed a severe disease, whereas heterozygous patients from the two autosomal dominant families that segregated the R120W mutation showed a milder phenotype.

- We also report a de novo mutation, T157P, which has not been previously described. Haplotype analysis of the CMT4A locus confirmed a unique origin for the Q163X mutation in 13 Spanish chromosomes and six American Hispanic chromosomes. A common origin for two Spanish chromosomes and two Moroccan chromosomes carrying the S194X was also confirmed.

- We concluded that: (i) although it used to be considered that CMT4A was inherited as an autosomal recessive disorder, some mutations may be expressed in heterozygous patients and segregate dominantly in some families; (ii) GDAP1 mutations are relatively frequent in our population, thus, the gene could be included in the routine genetic testing of CMT regardless of the inheritance pattern; and (iii) the most frequent mutation, Q163X, is the result of a founder effect as the consequence of a unique origin.

Abbreviations: $\mathrm{CHN}$, congenital hypomyelinating neuropathy; $\mathrm{CMAP}$ compound motor action potential; CMT disease, Charcot-Marie-Tooth disease; DSN, Déjérine-Sottas neuropathy; NCVs, nerve conduction velocities; SNAP, sensory nerve action potential 
chromosome 8q21.1. GDAPl is a 358 amino acid protein whose function is not well known. It is expressed in both the central and peripheral nervous system. ${ }^{16}{ }^{17}$ A putative role as glutathione S-transferases has been postulated for GDAP1. ${ }^{16}{ }^{17}$

Mutations in the GDAPI gene have been observed particularly in patients from Mediterranean countries, ${ }^{15}{ }^{16}$ 18-22 but also in those from other European regions. ${ }^{152324}$ The most prevalent mutation in Spain is Q163X, ${ }^{16}$ which has also been found in three North American Hispanic families. ${ }^{25}$ Moreover, S194X, the most frequent mutation in North African countries-Morocco, Tunisia ${ }^{15}{ }^{19}{ }^{21}$ - has also been found in Spain. ${ }^{16}$ Haplotype analysis of one Moroccan family and one Spanish family suggested a common origin of the S194X mutation found in both countries. ${ }^{18}$

We report here the genetics of CMT4A investigated through genetic analysis of the GDAPI gene and locus in a series 125 isolated or familial CMT patients with Spanish ancestry. We show that the most frequent mutation, Q163X, has a common origin in families from both Spain and North America. We also present genetic data suggesting that CMT4A displays both autosomal recessive and autosomal dominant inheritance, and we document a possible correlation between the severity of the disease and genetic status.

\section{METHODS \\ Patients}

A cohort of 161 patients belonging to 125 families with Spanish ancestry and with a diagnosis of CMT disease, either axonal or demyelinating, was available for genetic analysis of GDAP1. The cohort was distributed as follows: 106 isolated cases, 13 families with autosomal recessive inheritance (categorised thus because more than one sib was affected and parents were normal by examination or history), and six families with autosomal dominant inheritance. Consanguinity was observed in 10 isolated cases and three families. In all cases mutations in the PMP22, MPZ, and GJB1 genes had previously been excluded. Mutation analysis ${ }^{16}$ and clinical descriptions ${ }^{26}$ for families LF38, LF249, and LF20 has previously been reported. Mutation studies and clinical data of the Hispanic families HOU531, HOU364, and HOU726, have also been reported elsewhere. ${ }^{25}$ Informed consent was obtained from patients and relatives before genetic studies. The study was approved by both the Hospital Universitari $\mathrm{La} \mathrm{Fe}$ and the CSIC Institutional Boards on Bioethics.

\section{SSCP analysis and DNA sequencing}

The primers used for amplification of exons 1-6 have been reported elsewhere ${ }^{16}$ except a new direct primer for exon 1. The new designed primer is: 5'-CGCCCTCCTTCCGGCAGG TACC- $3^{\prime}$. PCR conditions were set as follows: 4 min initial denaturation at $95^{\circ} \mathrm{C}, 35$ cycles of $30 \mathrm{~s}$ denaturation at $94^{\circ} \mathrm{C}$, $30 \mathrm{~s}$ annealing and elongation at $54-69^{\circ} \mathrm{C}$ (exon $1,68^{\circ} \mathrm{C}$; exon $2,55^{\circ} \mathrm{C}$; exon $3,60^{\circ} \mathrm{C}$; exon $4,54^{\circ} \mathrm{C}$; exon $5,60^{\circ} \mathrm{C}$; and exon 6 , $69^{\circ} \mathrm{C}$ ), and a 7 min final extension at $72^{\circ} \mathrm{C}$.

For single-strand conformation polymorphism (SSCP) analysis, $5 \mu \mathrm{l}$ of PCR products were diluted in $3 \mu \mathrm{l}$ of $250 \mathrm{mM}$ EDTA, 98\% deionised formamide, $0.25 \%$ xylene cyanol, and $0.25 \%$ bromophenol blue. DNA was denatured for $10 \mathrm{~min}$ at $95^{\circ} \mathrm{C}$ and was kept on ice for more than $2 \mathrm{~min}$. Then $6 \mu \mathrm{l}$ of the mix was loaded onto $12 \%$ polyacrylamide with or without $5 \%$ glycerol. The non-denaturing gels were run at $800 \mathrm{~V}$ for $16 \mathrm{~h}$ at room temperature and visualised by silver staining.

Mutation screening was performed by direct sequencing of purified PCR products (Qiagen, Hilden, Germany) in an ABI PRISM 3100 sequencing analyser by using fluorescent dideoxynucleotides and one of the PCR primers. All sequences on both strands were determined.

\section{Microsatellite and SNP genotyping}

Genotyping for the six microsatellite markers linked to the CMT4A locus was performed using a similar PCR protocol: 4 min initial denaturation at $95^{\circ} \mathrm{C}, 35$ cycles of $30 \mathrm{~s}$ denaturation at $94^{\circ} \mathrm{C}, 30 \mathrm{~s}$ annealing and elongation at $55^{\circ} \mathrm{C}$ (D8S279, D8S286, and D8S551) or $58^{\circ} \mathrm{C}$ (D8S1474, D8S1289, and D8S84), and a $7 \mathrm{~min}$ final extension at $72^{\circ} \mathrm{C}$. PCR products were run on a $12 \%$ non-denaturing polyacrylamide gel at $800 \mathrm{~V}$ for $10 \mathrm{~h}$ at room temperature. Allele fragments were visualised by silver staining. Allelic numbers for every marker except D8S1474 are according to the Genome Database (http://www.gdb.org/). D8S1474 alleles and frequencies were established in the general Spanish population. The determination of haplotype phase was based either on homozygosity or on analysis of parental samples, which allowed us to fully or partially define the phase.

Analysis of the c.507T/G single nucleotide polymorphism (SNP) was performed by PCR amplification of exon 4 and restriction digestion with $D$ deI. After digestion the presence of two bands of 168 and $120 \mathrm{bp}$ indicates allele T, whereas a 288 bp undigested band indicates allele G. Both rs1025928 and rs959424 SNPs (UCSC Human Genome Browser, Human Genome Working Draft, http://genome.ucsc.edu/goldenPath/ septTracks.html) were investigated by SSCP analysis.

Estimation of Q163X mutation age was performed by means of the maximum likelihood method implemented in the program BDMC21 v2.1 (available at http://www.rannala. org/labpages/software.html). ${ }^{27}$ The program parameter setting we used were: growth rate $=0.005$, sample fraction $=$ 0.0000325 (assuming a carrier frequency of $1 / 200$ in the general population, a total population size of 40 million individuals, and a mutation rate of short tandem repeat (STR) linked markers of 0.0001). Program data settings were: 13 mutant copies, which are the mutant alleles in our sample, and two segregating sites. Program option settings were: conditional on copy number $=$ yes, number of Monte Carlo replicates $=10000$, initial time $=10$, final time $=500$, and interval increments $=10$.

Exclusion of false paternity was performed by using 10 microsatellite markers with high heterozygosity from the CHLC Human Screening Set/Weber version 6 (Research Genetics, Huntsville, AL, USA): D1S518, D2S1326, D3S2459, D4S2368, D5S2494, D6S1956, D7S1808, D8S1477, D9S301, and D10S1432.

\section{RESULTS}

\section{Mutation analysis}

In order to investigate the frequency and type of GDAPI mutations in the Spanish population, we screened each coding exon and flanking intronic sequences of GDAPl for mutations in a series of 125 CMT probands from unrelated families or isolated cases. All patients had Spanish ancestry. We observed mutations in 12 probands. The mutations described elsewhere-Q163X, S194X, and T288fsX290 ${ }^{16}$ were found in one or more additional families. Three novel mutations were found (table 1). One patient with an S194X mutation in one chromosome presented a 4 bp AAAG deletion on the other chromosome. This deletion is a frameshift mutation that generates a stop codon at position 145 (E114fsX145) and predicts a major disruption of GDAPl synthesis. Two mutations were missense amino acid changes, R120W and T157P. The R120W mutation was found in the heterozygous state in two families segregating the CMT phenotype as an autosomal dominant trait and the T157P mutation was detected in one sporadic case again expressing the disease as a dominant trait (fig 1). We found no other 
mutations in the dominant patients after sequencing all exons. Comparison of the mutated amino acids with the corresponding amino acids in the orthologous genes of GDAPl in mouse, rat, and zebrafish, and the paralogous gene GDAPIL1, mapped on human chromosome 20, and its orthologues in mouse, rat, and zebrafish ${ }^{17}$ revealed that the two missense mutations were non-conservative substitutions that altered highly conserved amino acids (table 1 ). Moreover, we did not find these nucleotide changes in 196 control chromosomes in individuals from the general Spanish population, suggesting again that neither R120W nor T157P are neutral polymorphisms. In short, we found 21 chromosomes bearing a GDAPI mutation in five families and seven sporadic cases.

\section{Mendelian inheritance}

Both types of CMT4A, demyelinating and axonal, were originally described in families segregating the disease as an autosomal recessive trait. Further studies have confirmed that patients carry two mutations and healthy parents are heterozygotes. By analysing the present series we found two families and one sporadic case with just one mutation in the coding sequence of the gene. In family LF292, the R120W mutation segregates with the disease phenotype in three generations (fig lA). The mutation was associated with an extended haplotype constructed with microsatellite markers D8S279 to D8S84 (figs IA and 2). In family LF293 we detected the R120W mutation in two affected brothers (fig $1 \mathrm{~B}$ ). In this family the parents were not available for genetic and clinical studies but the father was affected by history. The proband from family VAL8 was heterozygous for the T157P mutation (fig 1C); the mutation was not found in the parents. By genotyping 10 non-linked STRs we excluded false paternity and we confirmed that the mutation is a de novo event. Taken as a whole, the three families represent expression of the CMT phenotype as a dominant disorder.

\section{Phenotypic variability}

In order to correlate the mutations and inheritance patterns with disease severity, electrophysiological data and information on the clinical features of probands were compiled (table 2). Patients carrying two mutations and recessive inheritance showed a severe phenotype with very early onset in infancy and were wheelchair bound at the end of their first or the beginning of their second decade. In family LF38 affected members needed a wheelchair by the age of $30 .{ }^{26}$ By

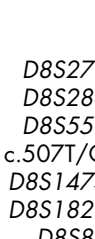

D8S84

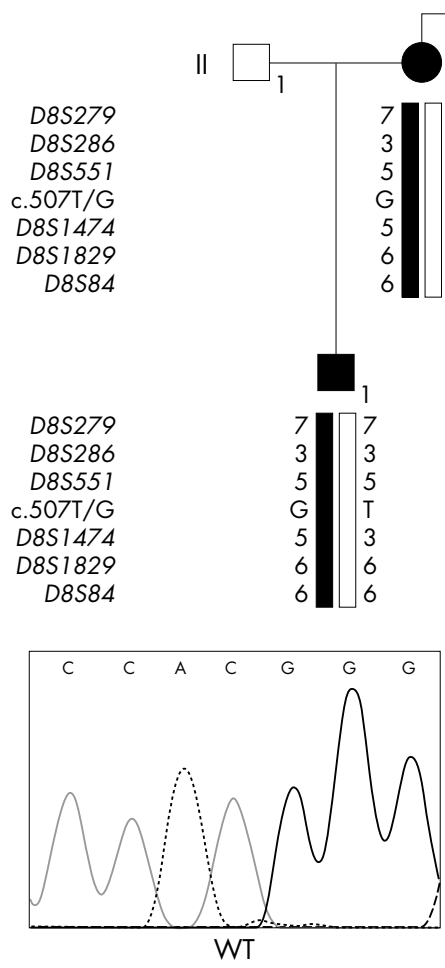

LF292

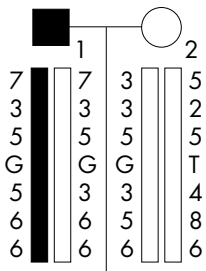

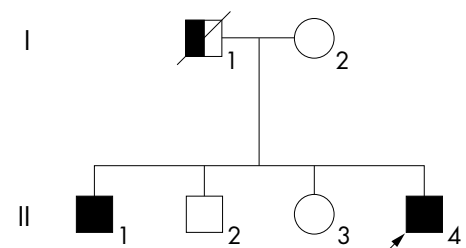

Figure 1 Pedigrees, mutations, and haplotype segregation of autosomal dominant CMT4A families. Affected individuals are indicated by filled symbols, unaffected individuals by unfilled symbols. Direct sequences of GDAPI mutations are identified in the three probands. Wild type sequence is on the left and mutation is on the right for each family. (A) Family LF292 with three affected generations; below the symbol for each individual are the genotypes for seven markers; the shared disease associated haplotype is in black. (B) Family LF293 for which dominant segregation is postulated because of involvement of the dead father by history (indicated as a half filled symbol). (C) Sporadic patient as the consequence of a de novo T157P mutation.
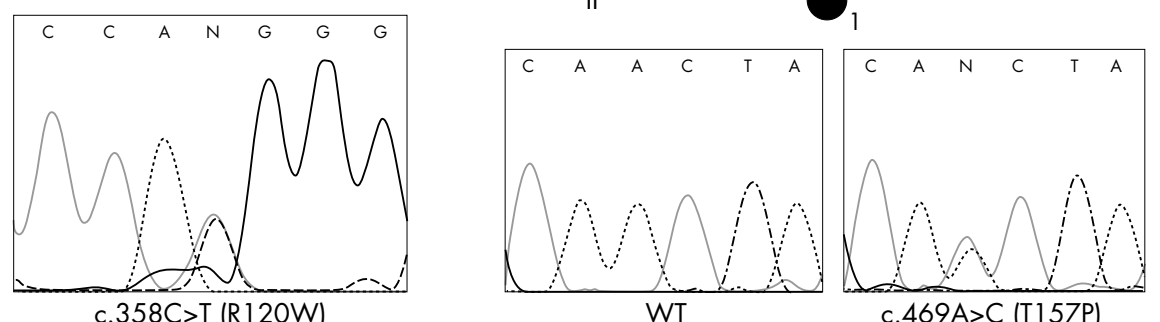


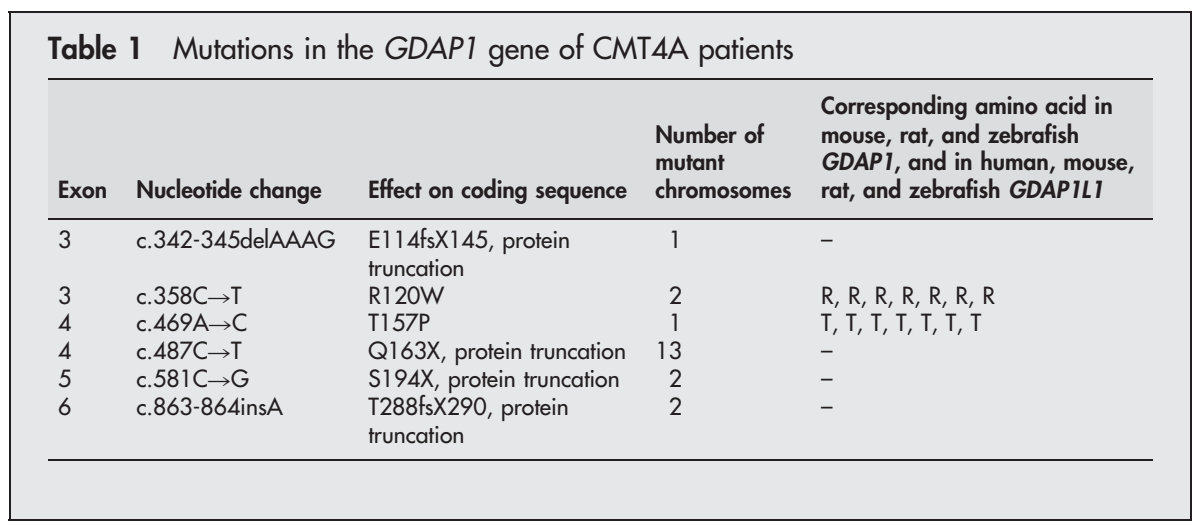

contrast, patients from the dominant families LF292 and LF293, which carry the identical mutation Rl20W, show a mild phenotype with onset at the end of second decade and very slow evolution. They are currently able to walk and need no orthopaedic devices. Muscle strength and deep tendon reflexes were more affected in recessive than in dominant patients. A hoarse voice was evident in patients from seven of eight recessive families but not in patients from dominant families. The sporadic patient from family VAL8 is a 9 year old girl who shows a severe phenotype with early onset of symptoms in the first year of life, moderately reduced distal strength in lower limbs, absent tendon reflexes, and optic atrophy.

It is noteworthy that electrophysiologic studies indicated that all patient except for probands from families LF127 and LF135 showed normal or mildly reduced NCVs. In these two patients, however, both compound motor action potential (CMAP) and sensory nerve action potential (SNAP) were strongly reduced. These findings suggest that the main lesion in all patients is localised to the axon.

\section{Haplotype analysis and founder effect}

We found four mutations in more than one chromosome (table 1). To determine whether each mutation had a common ancestral origin, we proceeded to investigate the presence of a shared common haplotype. To construct haplotypes we searched for SNPs in the coding sequence and flanking intronic sequences of GDAPl. After screening 224 chromosomes by SSCP analysis, we only found the c.507T/G SNP in the coding sequence (exon 4) which represents a synonymous change, S169S. This SNP has also been reported by others. ${ }^{25}$ We then proceeded to construct extended haplotypes by analysis of six flanking STR markers, D8S279, D8S286, D8S551, D8S1474, D8S1829, and D8S84, which span $\sim 2.83 \mathrm{Mb}$ around the CMT4A locus (fig 2).

The most frequent mutation in our series was Q163X. Five patients were homoallelic for Q163X and three patients were

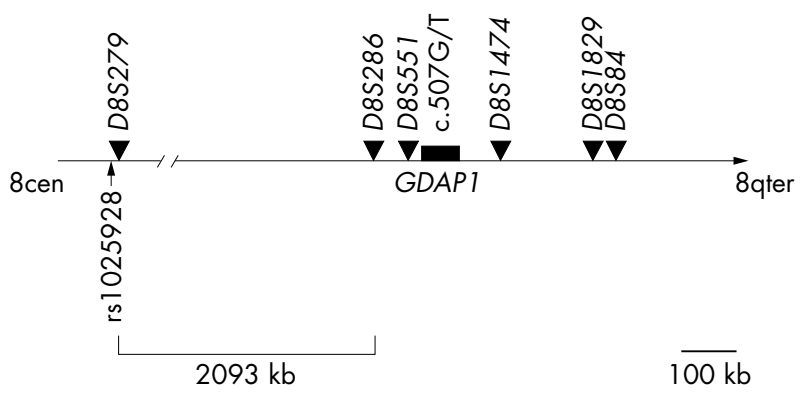

Figure 2 Physical map of the CMT4A locus. The GDAPI gene is indicated as a box. Linked microsatellite markers are indicated at the top. The rs 1025928 SNP at the D8S279 locus is shown at the bottom. compound heterozygous for Q163X and a different mutation. Four patients, including three homozygotes, came from valleys in the Basque Country; thus, seven Q163X bearing chromosomes had a Basque origin. The other six mutant chromosomes came from Castile and Leon and the Valencia region of Spain (fig 3).

We constructed haplotypes at the CMT4A locus in our families. When considering only the D8D551-c.507G/TD8S1474 core haplotype in the Spanish patients, three different haplotypes were associated with the Q163X mutation: the main haplotype 5-G-3 was observed in 11 chromosomes, whereas haplotypes 4-G-3 and 5-G-2 were associated with chromosomes $\mathrm{C}$ and $\mathrm{F}$, respectively (fig 4 ). The observed allele variations represent a change of just one repeat that could be produced by mutation. Thus, we suggested that the three haplotypes represent a common ancestral haplotype (the $\mathrm{C}$ and $\mathrm{F}$ chromosomes) caused by mutations of repeat elements. We postulated that the Q163X mutation originated once in the Iberian peninsula and that the present patients and families segregating the CMT4A phenotype are the consequence of a founder effect.

To confirm this hypothesis we extended haplotype analysis with more STRs. Analysis of all markers again suggested the presence of a common ancestral haplotype 7-3-5-G-3-6-6. Seven out of 13 Spanish chromosomes shared the complete haplotype, while we found variations in some STRs in the other six chromosomes (fig 4). We observed different alleles at markers D8S286 and D8S1829 on chromosome C. This finding suggests chromosome $\mathrm{C}$ derived from the ancestral chromosome after several mutation or recombination events.

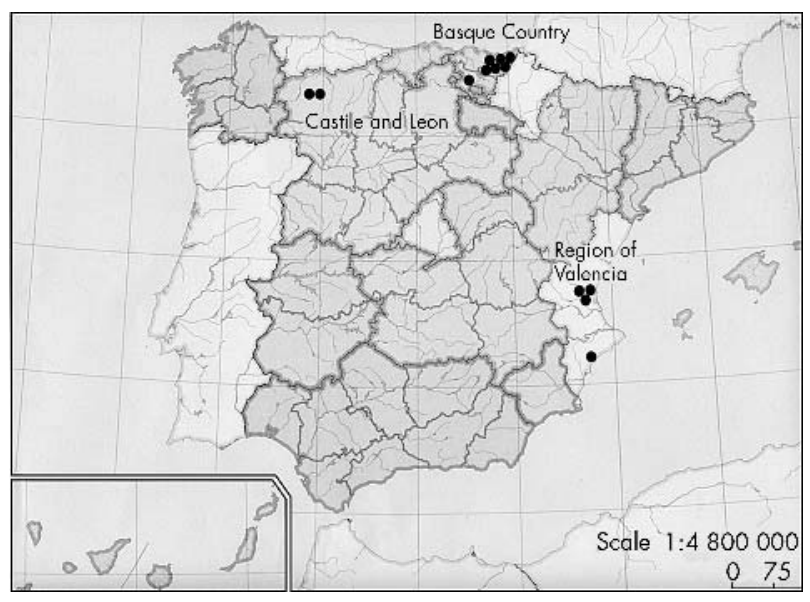

Figure 3 Map of Spain showing the 17 autonomous regions. Chromosomes bearing Q163X mutations are represented as filled circles: there are seven in the Basque Country, four in the Valencia region, and two in Castile and Leon. 


\begin{tabular}{|c|c|c|c|c|c|c|c|c|c|c|c|}
\hline \multirow[b]{2}{*}{ Family } & \multirow[b]{2}{*}{$\begin{array}{c}\text { Chromosome } \\
\text { no. }\end{array}$} & \multirow[b]{2}{*}{ rs 1025928} & \multicolumn{3}{|c|}{ 5' flanking markers } & \multirow{2}{*}{$\begin{array}{c}\text { GDAPI SNP } \\
\text { c.507G/T }\end{array}$} & \multicolumn{3}{|c|}{ 3' flanking STRs } & \multirow[b]{2}{*}{ Ethnic origin } & \multirow[b]{2}{*}{ Ref. } \\
\hline & & & D8S279 & D8S286 & D8S551 & & D8S1474 & D8S1829 & D8S84 & & \\
\hline \multirow[t]{2}{*}{ LF38 } & A & C & 7 & 3 & 5 & $G$ & 3 & 6 & 6 & \multirow[t]{2}{*}{ Spain/Leon } & \multirow[t]{2}{*}{ PR, Cuesta et al ${ }^{16}$} \\
\hline & B & C & 7 & 3 & 5 & G & 3 & 6 & 6 & & \\
\hline LF249 & C & C & 7 & 2 & 4 & G & 3 & 5 & 6 & Spain/Valencia & PR, Cuesta et al ${ }^{16}$ \\
\hline LF20 & D & C & 7 & 3 & 5 & G & 3 & 6 & 6 & Spain/Valencia & PR, Cuesta et al ${ }^{16}$ \\
\hline \multirow[t]{2}{*}{ LF135 } & $\mathrm{E}$ & C & $5 \mathrm{mut}$ & 3 & 5 & $G$ & 3 & 6 & 6 & \multirow[t]{2}{*}{ Spain/Valencia } & \multirow[t]{2}{*}{$P R$} \\
\hline & $\mathrm{F}$ & $T$ & $5 \mathrm{rec}$ & 3 & 5 & G & 2 & 6 & 6 & & \\
\hline \multirow[t]{2}{*}{ VALI } & G & C & 7 & 3 & 5 & G & 3 & 6 & 6 & \multirow[t]{2}{*}{ Spain/Basque } & \multirow[t]{2}{*}{ PR } \\
\hline & $\mathrm{H}$ & C & $5 \mathrm{mut}$ & 3 & 5 & G & 3 & 6 & 6 & & \\
\hline \multirow[t]{2}{*}{ VAL3 } & 1 & C & $6 \mathrm{mut}$ & 3 & 5 & G & 3 & 6 & 6 & \multirow[t]{2}{*}{ Spain/Basque } & \multirow[t]{2}{*}{ PR } \\
\hline & J & $\mathrm{T}$ & 3 rec & 3 & 5 & G & 3 & 6 & 6 & & \\
\hline \multirow[t]{2}{*}{ VAL4 } & K & C & 7 & 3 & 5 & G & 3 & 6 & 6 & \multirow[t]{2}{*}{ Spain/Basque } & \multirow[t]{2}{*}{ PR } \\
\hline & $\mathrm{L}$ & C & 7 & 3 & 5 & G & 3 & 6 & 6 & & \\
\hline VAL5 & M & C & 7 & 3 & 5 & G & 3 & 6 & 6 & Spain/Basque & PR \\
\hline \multirow[t]{2}{*}{ HOU364 } & N & C & 7 & 3 & 5 & G & 3 & 6 & 6 & \multirow[t]{2}{*}{ Costa Rica } & \multirow[t]{2}{*}{ PR, Boerkoel et al ${ }^{25}$} \\
\hline & O & C & 7 & 3 & 5 & G & 3 & 6 & 6 & & \\
\hline \multirow[t]{2}{*}{ HOU726 } & $P$ & C & 7 & 3 & 5 & G & 3 & 6 & 6 & \multirow[t]{2}{*}{ Costa Rica } & \multirow[t]{2}{*}{ PR, Boerkoel et al $\left.\right|^{25}$} \\
\hline & $Q$ & C & 7 & 3 & 5 & G & 3 & 6 & 6 & & \\
\hline \multirow[t]{2}{*}{ HOU531 } & R & $T$ & $3 \mathrm{rec}$ & 3 & 5 & G & 3 & 6 & 6 & \multirow[t]{2}{*}{ Peru } & \multirow[t]{2}{*}{ PR, Boerkoel et al ${ }^{25}$} \\
\hline & $S$ & C & $5 \mathrm{mut}$ & 3 & 5 & $G$ & 3 & 6 & 6 & & \\
\hline
\end{tabular}

PR, present report

Figure 4 GDAP1 haplotypes associated with the Q163X mutation. The figure shows haplotypes associated with the 13 Spanish chromosomes (A to $\mathrm{M}$ ) and the six (N to S) Hispanic North American chromosomes bearing the Q163X mutation. Families are indicated in the first column. Ethnic origin is indicated. A grey colour code is used to identify the marker alleles shared by all chromosomes. Alleles for some markers diverge from the common ancestral haplotype. Light grey labelling indicates that it may have been generated by mutation (mut); by contrast, white labelling suggests that it was the result of a recombination event (rec).

However, since flanking markers D8S279 (allele 7 represents $0.08 \%$ of normal chromosomes) and D8S84 (allele 6 represents $0.54 \%$ of normal chromosomes) did not change with regard to the common haplotype, we suggest a unique origin for the Q163X mutation is most likely. At locus D8S279 the ancestral chromosome is split into three different haplotypes: three chromosomes carry allele 5 (chromosomes E, F, and H), one chromosome allele 3 (chromosome J), and another chromosome allele 6 (chromosome I). To determine if variation was generated by recombination (D8S279 maps $2.1 \mathrm{Mb}$ away from D8S286) or by mutation of repeats, we extended the genotype of the D8S279 locus with closely linked SNPs. We reasoned that analysis of closely linked SNPs would reduce the risk of marker mutation whereas the chance of recombination is minimal. We typed rs1025928 (allele $\mathrm{T} 70 \%$, allele C $30 \%$ in the normal population) in patients. We observed five allele segregations of rs1025928D8S279 markers in Spanish chromosomes: C-7, T-5, C-5, T-3, and C-6. We postulated that the short haplotype C-7 represents the ancestral chromosome carrying the C-7-3-5G-3-6-6 extended haplotype. Thus, when allelic variation at D8S279 was associated with allele C we interpreted it as the consequence of mutation (chromosomes $\mathrm{E}, \mathrm{H}$, and I), whereas the presence of allele $\mathrm{T}$ suggested that variation at D8S279 was the consequence of a recombination event (chromosomes $\mathrm{F}$ and $\mathrm{J}$ ). By using intra-allelic variability of the closest markers D8S551 and D8S1474, we estimated the age of the Q163X mutation to be approximately 33000 years old (1650 generations, 20 year generations).

Recently, Boerkoel et al ${ }^{25}$ reported three North American Hispanic families from Texas with patients homozygous for the Q163X mutation. Two families came from Costa Rica (families HOU364 and HOU726) and one from Peru (family HOU531). Since patients of the three families shared a common haplotype and they are Hispanic in origin, a founder mutation originating in the Iberian peninsula was postulated. To confirm this hypothesis we compared haplotypes at the CMT4A locus with those of the Spanish patients. We observed that four of the Hispanic chromosomes shared the common haplotype C-7-3-5-G-3-6-6 with Spanish chromosomes. The other two chromosomes showed allelic differences for the proximal markers rs 1025928 and D8S279 (fig 4). These data confirm that the Q163X mutation in patients from both sides of the Atlantic has a common ancestral origin and suggest the existence of a founder effect for the Q163X mutation in the Iberian peninsula. Interestingly, we observed identical variation at locus D8S279 in both Spanish and Hispanic chromosomes. Chromosomes $\mathrm{R}$ and $\mathrm{J}$ share the same haplotype, whereas chromosome $\mathrm{S}$ has the identical haplotype to chromosomes $\mathrm{E}$ and $\mathrm{H}$. These findings suggest two possible hypotheses about migration: first, the Q163X mutation moved from Spain to America once, probably associated with allele 7, and later the other haplotypes appeared either by recombination or by mutation; second, the Q163X mutation arrived into America in more than one migration movement.

We also applied haplotype analysis to the other mutations each found in two chromosomes: S194X and T288fsX290 (fig 5). We observed that every mutation could be associated with a unique haplotype confirming a unique origin for each one. The S194X mutation was associated with a common D8S551 to D8S84 haplotype in the two Spanish chromosomes. By studying the extended haplotype in the Moroccan family PN860 we confirmed that S194X mutations have a common 


\begin{tabular}{|c|c|c|c|c|c|c|c|c|c|c|}
\hline \multirow[b]{2}{*}{ Mutation } & \multirow[b]{2}{*}{ Family } & \multicolumn{3}{|c|}{ 5' flanking STRs } & \multirow{2}{*}{$\begin{array}{c}\text { GDAPl } \\
\text { SNP } \\
\text { c.507G/T }\end{array}$} & \multicolumn{3}{|c|}{ 3' flanking STRs } & \multirow[b]{2}{*}{ Origin } & \multirow[b]{2}{*}{ Ref. } \\
\hline & & D8S279 & D8S286 & D8S551 & & D8S1474 & D8S1829 & D8S84 & & \\
\hline \multirow[t]{4}{*}{ S194X } & LF249 & 3 & 4 & 2 & $\mathrm{~T}$ & 1 & 5 & 5 & Spain & PR, Cuesta et al ${ }^{16}$ \\
\hline & LF 127 & 7 & 3 & 2 & $\mathrm{~T}$ & 1 & 5 & 5 & Spain & PR \\
\hline & PN860 & 6 & 4 & 2 & $T$ & 1 & 5 & 5 & \multirow[t]{2}{*}{ Morocco } & \multirow[t]{2}{*}{ PR, Nelis et al ${ }^{18}$} \\
\hline & & 6 & 4 & 2 & $\mathrm{~T}$ & 1 & 5 & 5 & & \\
\hline \multirow[t]{2}{*}{ T288fsX290 } & LF20 & 5 & 3 & 5 & $\mathrm{~T}$ & 1 & 6 & 7 & Spain & PR, Cuesta et al ${ }^{16}$ \\
\hline & LF 127 & 5 & 3 & 5 & $\mathrm{~T}$ & 2 & 5 & 6 & Spain & PR \\
\hline
\end{tabular}

PR, present report

Figure 5 GDAP1 haplotypes associated with S194X and T288fsX290 mutations in Spanish and Moroccan chromosomes. Shared alleles for each marker are indicated by a grey shading. When a recombination event is suspected alleles are labelled in white.

origin in Spain and Morocco, as previously reported by Nelis et al. ${ }^{18}$ The two chromosomes bearing the T288fsX290 mutation shared a common haplotype between markers D8S279 and c.507G/T, but differed in the three distal markers. This difference suggests that a recombination event occurred between GDAPI and D8S1474.

\section{DISCUSSION}

The genetics of motor and sensory hereditary neuropathies is complex. These disorders show a wide phenotypic and genetic heterogeneity. We addressed the genetics of CMT4A in a series of 125 unrelated families with Spanish ancestry. We found six different mutations in GDAPI, five previously reported $^{151623}$ and one new mutation, in 12 families. Interestingly, we found mutations in seven isolated cases, three autosomal recessive families previously reported, ${ }^{16}$ and two autosomal dominant families. Six out of seven sporadic patients were homozygotes or compound heterozygotes, whereas one patient was heterozygous for the T157P mutation that originated as a de novo mutation and, hence, was expressed as a dominant mutation. In any case there was a history of consanguinity. The seven sporadic patients represent a detection rate of $5.6 \%$ in the 106 isolated cases of the series, a screening yield suggesting that GDAPl testing may be indicated in the mutation analysis of isolated CMT patients. Nevertheless, as no mutation has been reported in isolated cases from other series, ${ }^{23}$ inclusion of GDAPl in the molecular diagnosis routine of CMT may depend on the prevalence of CMT4A in each country.

Autosomal dominant inheritance has not previously reported in CMT patients and families with GDAPI gene mutations. Patients from families LF292 and LF293 carried the R120W mutation and segregated the disease as an autosomal dominant trait. They showed a mild phenotype with age of onset in the second decade or even later and are still walking (I-1 in family LF292 is 70 years old). This mild phenotype in heterozygous patients is in contrast with the apparently healthy parents of patient CMT-82.3 reported by Ammar et $a^{23}$ who is compound heterozygous for the Rl20W and G271R mutations. However, while the patient inherited the G27IR mutation from her mother, the Rl20W mutation had to be inherited from her deceased father; thus, it is impossible to know whether or not the father would have developed the symptoms of CMT disease. It is possible that Rl20W substitution may produce a mild clinical picture in heterozygotes but a more severe phenotype when it is associated with another mutation.

The Q163X mutation is clearly the most frequent mutation in Spain. It has not been found in patients from other countries except for three Hispanic North American families.
These three families shared a common associated haplotype indicating a founder mutation with a possible origin in the Iberian peninsula. ${ }^{25}$ Haplotype analysis suggests that the Q163X mutation in several families from different regions in Spain is the consequence of a founder effect that we have dated to many centuries ago, and confirms the Spanish origin of the mutant chromosomes in the Hispanic families. Interestingly, identical variations at markers rs1025928 and D8S279 found in the Spanish chromosomes (chromosomes E, $\mathrm{H}$, and $\mathrm{J}$ ) were also observed in the Hispanic chromosomes (chromosomes $\mathrm{R}$ and $\mathrm{S}$ ). This coincidence suggests that D8S279 divergence might have occurred before carrier individuals went to America. Thus, the most likely series of events is that Q163X migrated from the Iberian peninsula to America in three separate migrations. Seven out of 13 Spanish chromosomes are from the Basque Country, six of them from two valleys close together in the province of Guipuzkoa. Chromosomes $\mathrm{H}$ and $\mathrm{J}$ have been found in two Basque patients while the other Basque patients carry the common ancestral chromosomes also found in other Spanish patients. Since chromosomes $\mathrm{H}$ and $\mathrm{J}$ are identical to chromosomes $\mathrm{S}$ and $\mathrm{R}$, respectively, we propose that the latter arrived in Peru from the Basque Country. By contrast, determination of the origin of the four Costa Rican chromosomes is more difficult because we have no data on the origin of the mutation or the distribution of the ancestral chromosome in the Iberian peninsula.

We estimated the age of the Q163X mutation to be 33000 years, which makes it a relatively ancient mutation. It predates the most recent Neolithic expansion of modern humans into Europe, roughly 10 000-15 000 years ago, and corresponds more closely with the early Palaeolithic expansion. ${ }^{28}$ It is interesting to speculate that the mutation may have originated in or arrived into the Basque Country and then extended to the rest of the Iberian peninsula.

A second mutation, S194X, has been described both in Spanish families ${ }^{16}$ and in Tunisian $^{15}$ and Moroccan families ${ }^{18}{ }^{19}$ from the countries referred to as the Maghreb (Morocco, Algeria, and Tunisia). As previously reported, ${ }^{18}$ we have confirmed the common origin of this mutation in two unrelated Spanish families and one Belgian family with Moroccan ancestry. Moreover, we also observed that the T288fsX290 mutation, found in two chromosomes from unrelated families, has a common origin. In total, we have demonstrated that three mutations in the Spanish population are the consequence of founder effects.

In summary, both the genetics of the GDAPI gene and clinical expression of CMT4A neuropathy is complex. Most families segregate the neuropathy as a recessive trait although some families show dominant segregation of mutations that may be associated with a milder phenotype. 


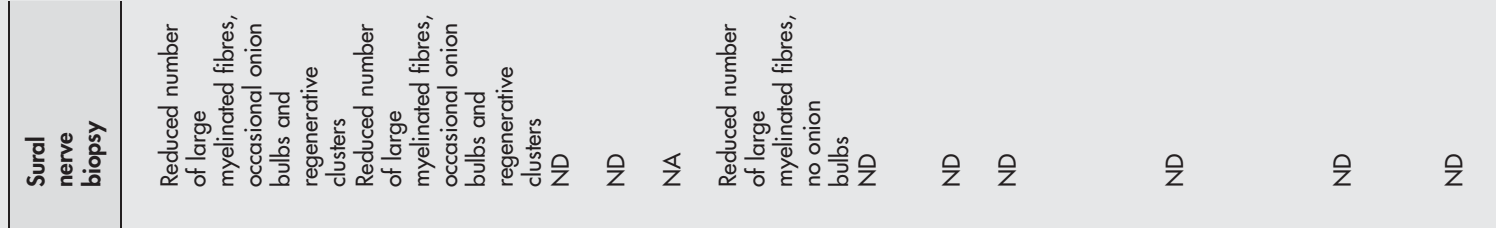

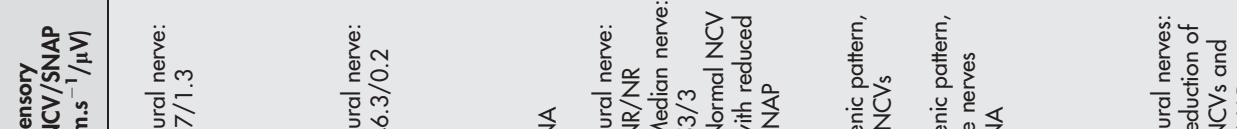

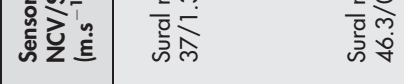

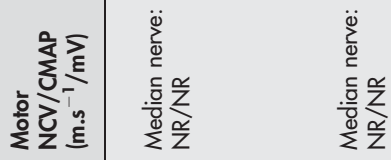

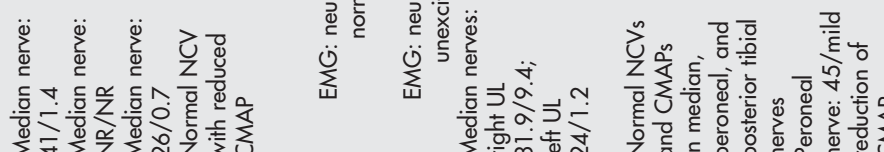

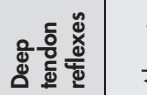

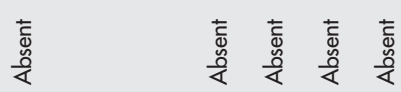

毫嘉高

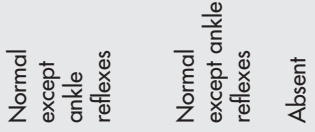

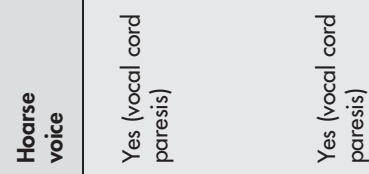

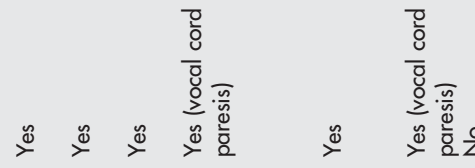

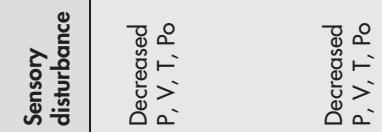

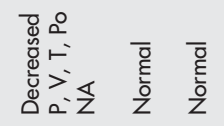

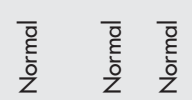

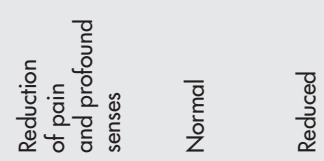

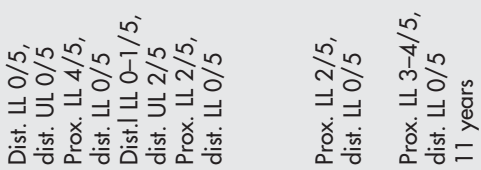

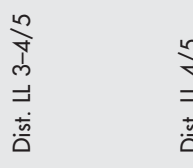

$8 \div \frac{1}{2} \circ \times \frac{9}{3}$

$\frac{9}{3}$

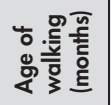

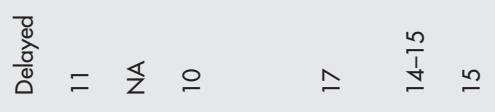

$\underline{z}$

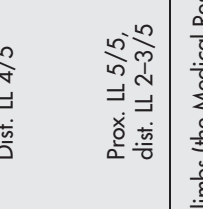

高毫旁

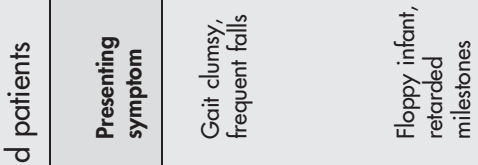

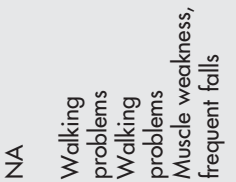

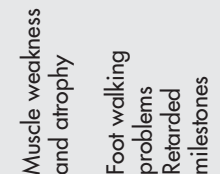

$\frac{\text {. }}{\bar{y}}$

I

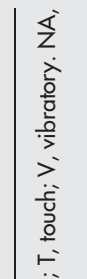

0
$\frac{0}{0}$
$\frac{0}{0}$
$\frac{0}{2}$
$\frac{5}{5}$
$\frac{5}{3}$
0

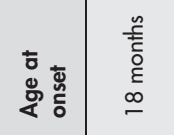

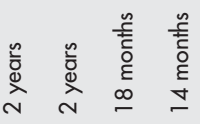

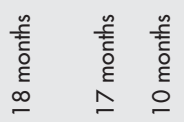

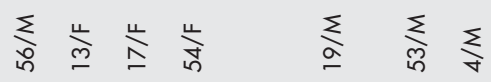

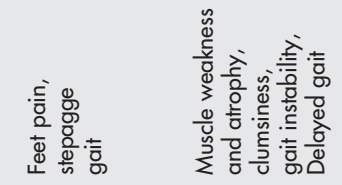

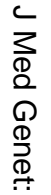

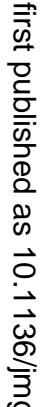

ஸे

:

$\vec{\infty}$

인

을.

:

인

产

$\vec{\circ}$

镸

言

3.

ڤे

N

इ

$\stackrel{\circ}{\bar{D}}$

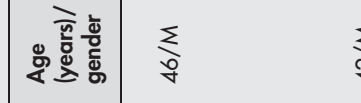

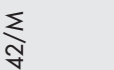

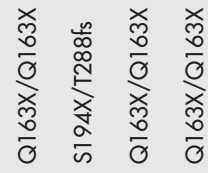

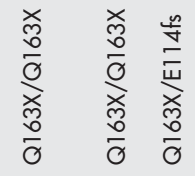

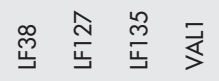

总素举

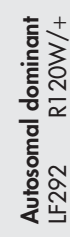

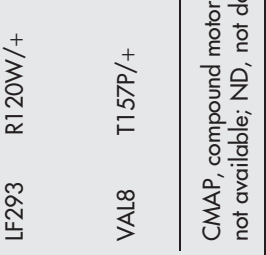

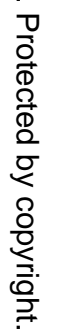


Finally, most of the mutations causing the rare disease of CMT4A originated once in human history.

\section{ACKNOWLEDGEMENTS}

We are grateful for the kind collaboration of patients and families We also thank Dr E Nelis and Dr V Timmerman for providing DNA samples from family PN860.

\section{ELECTRONIC-DATABASE INFORMATION}

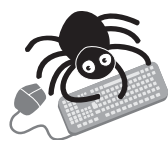

The URLs mentioned in this study are as follows: Genome Database, http://www.gdb.org/; UCSC Human Genome Browser, Human Genome Working Draft, http://genome.ucsc.edu/goldenPath/ septTracks.html; and BDMC21 v2.1 software available from http://www.rannala.org/labpages/ software.html.

\section{Authors' affiliations}

R Claramunt, L Pedrola, A Cuesta, B Sánchez-Navarro, C Espinós, F Palau, Laboratory of Genetics and Molecular Medicine, Department of Genomics and Proteomics, Instituto de Biomedicina, CSIC, Valencia, Spain

T Sevilla, J J Vilchez, Department of Neurology, Hospital Universitari La $\mathrm{Fe}$, Valencia, Spain

A López de Munain, Department of Neurology, Hospital Donostia, San Sebastian, Spain

J Berciano, Department of Neurology, Hospital Universitario Marqués de Valdecilla, Universidad de Cantabria, Santander, Spain

J M Millán, Genetics Unit, Hospital Universitari La Fe, Valencia, Spain G M Saifi, J R Lupski, Department of Molecular and Human Genetics, Baylor College of Medicine, Houston, TX, USA

This work was supported by Spanish Ministry of Science and Technology grants SAF2000-0082-C02-01 and SAF2003-00135, Fundació "la Caixa" grant 02-004, Instituto de Salud Carlos III grant G03/56 for the Spanish Network on Cerebellar Ataxias, and the GIS-Maladies Rares Consortium on Autosomal Recessive CMT. RC is a predoctoral fellow receiving the Fundació "la Caixa" grant and LP is a recipient of a predoctoral fellowship from the Spanish Ministry of Science and Technology.

Competing interests: the authors declare that they have no competing financial interests.

Correspondence to: Dr Francesc Palau, Department of Genomics and Proteomics, Instituto de Biomedicina, CSIC, C/Jaume Roig 11, 46010 Valencia, Spain; fpalau@ibv.csic.es

Received 28 April 2004

Revised version received 23 June 2004

\section{REFERENCES}

1 Combarros O, Calleja J, Polo JM, Berciano J. Prevalence of hereditary motor and sensory neuropathy in Cantabria. Acta Scand Neurol 1987;75:9-12.

2 Lupski JR, Garcia CA. Charcot-Marie-Tooth peripheral neuropathies and related disorders. In: Scriver CR, Beaudet AL, Sly WS, Valle D, eds. The metabolic and molecular basis of inherited disease. 8th ed. New York: McGraw-Hill, 2001:5759-88.

3 Shy ME, Garbern JY, Kamholz J. Hereditary motor and sensory neuropathies: a biological perspective. Lancet Neurol 2002;1:110-8.

4 Suter U, Scherer SS. Disease mechanisms in inherited neuropathies. Nat Rev Neurosci 2003;4:714-26.

5 Saifi GM, Szigeti K, Snipes GJ, Garcia CA, Lupski JR. Molecular mechanisms, diagnosis, and rational approaches to management of and therapy for Charcot-Marie-Tooth disease and related peripheral neuropathies. J Invest Med 2003;51:261-83.

6 Hayasaka K, Himoro M, Sato W, Takada G, Uyemura K, Shimizu N, Bird TD, Conneally PM, Chance PF. Charcot-Marie-Tooth neuropathy type IB is associated with mutations of the myelin $\mathrm{P}_{0}$ gene. Nat Genet 1993;5:31-4.

7 Kulkens T, Bolhuis PA, Wolterman RA, Kemp S, te Nijenhuis S, Valentijn D, Hensels GW, Jennekens FG, de Visser M, Hoogendijk JE, Baas F. Deletion of the serine 34 codon from the major peripheral myelin protein $\mathrm{P}_{0}$ gene in Charcot-Marie-Tooth disease type 1B. Nat Genet 1993;5:35-9.

8 Marrosu MG, Vaccargiu S, Marrosu G, Vannelli A, Cianchetti C, Muntoni F. Charcot-Marie-Tooth disease type 2 associated with mutation of the myelin protein zero gene. Neurology 1998;50:1397-401.

9 De Jonghe P, Timerman V, Ceuterick C, Nelis E, De Vriendt E, Lofgren A, Vercruyssen A, Verellen C, Van Maldergem L, Martin JJ, Van Broeckhoven C. The Thr124Met mutation in the peripheral myelin protein zero (MPZ) gene is associated with a clinically distinct Charcot-Marie-Tooth phenotype. Brain 1999;122:281-90.

10 Hayasaka K, Himoro M, Sawaishi Y, Nanao K, Takahashi T, Takada G, Nicholson GA, Ouvrier RA, Tachi N. De novo mutation of the $P_{0}$ gene in Dejerine-Sottas disease (hereditary motor and sensory neuropathy type III). Nat Genet 1993:5:266-8.

11 Warner LE, Hilz M, Appel SH, Killian JM, Kolodry EH, Karpati G, Carpenter S, Watters GV, Wheeler C, Witt D, Bodell A, Nelis E, Van Broeckhoven C, Lupski JR. Clinical phenotype of different MPZ $\left(P_{0}\right)$ mutations may include Charcot-Marie-Tooth type 1B, Dejerine-Sottas, and congenital hypomyelination. Neuron 1996; 17:451-60.

12 Parman Y, Planté-Bordeneuve V, Guiochon-Mantel A, Eraksoy M, Said G. Recessive inheritance of a new point mutation of the $\mathrm{PMP}_{22}$ gene in DejerineSottas disease. Ann Neurol 1999;45:518-22.

13 Numakura C, Lin C, Oka N, Akiguchi I, Hayasaka K. Homeozygous mutation of peripheral myelin protein 22 gene associated with Charcot-Marie-Tooth disease type 1. Ann Neurol 2000;47:101-3.

14 Ben Othmane K, Hentati F, Lennon F, Ben Hamida C, Blel S, Roses AD, Pericak-Vance MA, Ben Hamida M, Vance JM. Linkage of a locus (CMT4A) for autosomal recessive Charcot-Marie-Tooth disease to chromosome 8q. Hum Mol Genet 1993;2:1625-8.

15 Baxter RV, Ben Othmane K, Rochelle JM, Stajich JE, Hulette C, Dew-Knight S, Hentati F, Ben Hamida M, Bel S, Stenger JE, Gilbert JR, Pericak-Vance MA, Vance JM. Ganglioside-induced differentiation-associated protein-1 is mutant in Charcot-Marie-Tooth disease type 4A/8q21. Nat Genet 2002;30:21-2.

16 Cuesta A, Pedrola L, Sevilla T, Garcia-Planells J, Chumillas MJ, Mayordomo F, LeGuern E, Marin I, Vilchez JJ, Palau F. The gene encoding gangliosideinduced differentiation-associated protein 1 is mutated in axonal CharcotMarie-Tooth type 4A disease. Nat Genet 2002;30:22-5.

17 Marco A, Cuesta A, Pedrola L, Palau F, Marin I. Evolutionary and structural analyses of GDAP1, involved in Charcot-Marie-Tooth disease, characterize a novel class of glutathione transferase-related genes. Mol Biol Evol 2004; $21: 176-87$.

18 Nelis E, Erdem S, Van Den Bergh PY, Belpaire-Dethiou MC, Ceuterick C, Van Gerwen V, Cuesta A, Pedrola L, Palau F, Gabreels-Festen AA, Verellen C, Tan E, Demirci M, Van Broeckhoven C, De Jonghe P, Topaloglu H. Timmerman V. Mutations in GDAP1: autosomal recessive CMT with demyelination and axonopathy. Neurology 2002;59:1865-72.

19 Azzedine H, Ruberg M, Ente D, Gilardeau C, Perie S, Wechsler B, Brice A, LeGuern E, Dubourg O. Variability of disease progression in a family with autosomal recessive CMT associated with a S194X and new R310Q mutation in the GDAP1 gene. Neuromuscul Disord 2003;13:341-6.

20 Birouk N, Azzedine H, Dubourg O, Muriel MP, Benomar A, Hamadouche T, Maisonobe T, Ouazzani R, Brice A, Yahyaoui M, Chkili T, Le Guern E. Phenotypical features of a Moroccan family with autosomal recessive CharcotMarie-Tooth disease associated with the S194X mutation in the GDAP1 gene. Arch Neurol 2003;60:598-604.

21 De Sandre-Giovannoli A, Chaouch M, Boccaccio I, Bernard R, Delague V, Grid D, Vallat JM, Lévy N, Mégarbané A. Phenotypic and genetic exploration of severe demyelinating and secondary axonal neuropathies resulting from GDAPI nonsense and splicing mutations. J Med Genet 2003;40:e87.

22 Senderek J, Bergmann C, Ramaekers VT, Nelis E, Bernert G, Makowski A, Zuchner S, De Jonghe P, Rudnik-Schoneborn S, Zerres K, Schroder JM. Mutations in the ganglioside-induced differentiation-associated protein-1 (GDAP1) gene in intermediate type autosomal recessive Charcot-Marie-Tooth neuropathy. Brain 2003;126:642-9.

23 Ammar N, Nelis E, Merlini L, Barisic N, Amouri R, Ceuterick C, Martin JJ, Timmerman V, Hentati F, De Jonghe P. Identification of novel GDAP mutations causing autosomal recessive Charcot-Marie-Tooth disease. Neuromuscul Disord 2003;13:720-8.

24 Stojkovic T, Latour P, Viet G, de Seze J, Hurtevent JF, Vandenberghe A, Vermersch P. Vocal cord and diaphragm paralysis, as clinical features of a French family with autosomal recessive Charot-Marie-Tooth disease, associated with a new mutation in the GDAP1 gene. Neuromuscul Disord 2004;14:261-4.

25 Boerkoel CF, Takashima H, Nakagawa M, Izumo S, Armstrong D, Butler I, Mancias P, Papasozomenos SC, Stern LZ, Lupski JR. CMT4A: identification of a Hispanic GDAP1 founder mutation. Ann Neurol 2003;53:400-5.

26 Sevilla T, Cuesta A, Chumillas MJ, Mayordomo F, Pedrola L, Palau F, Vilchez JJ. Clinical, electrophysiological and morphological findings of Charcot-Marie-Tooth neuropathy with vocal cord palsy and mutations in the GDAP1 gene. Brain 2003;126:2023-33.

27 Slatkin M, Rannala B. Estimating the age of alleles by use of intra-allelic variability. Am J Hum Genet 1997;60:447-58

28 Cavalli-Sforza LL, Menozzi P, Piazza A. The history and geography of human genes. Princeton, NJ: Princeton University Press, 1994:255-301. 